\title{
Hora da virada
}

\section{Renata Betarel}

betareli_re@hotmail.com

EE Professora Flávia Vizibeli Pirró - São Paulo -SP - Brasil

\section{Resumo}

A EE Professora Flávia Vizibeli Pirró é uma escola estadual, fundada e mantida pelo Governo do Estado de São Paulo, de porte médio, localizada na capital de São Paulo, em bairro periférico da zona sul, conhecido como Comunidade Alba. A unidade escolar atende alunos do Ensino Fundamental, Ciclo I e II.

A unidade escolar é mantida pelo Poder Público Estadual e administrada pela Secretaria do Estado da Educação, locada na Diretoria de Ensino de Centro Oeste.

Nossa ênfase é a educação, pautada em valores éticos, morais e sociais. A escola tem como Missão, oportunizar ao educando a construção efetiva de seu conhecimento, através de uma educação de qualidade, humanitária e adequada à sua realidade, visando qualidade de vida. E como visão, ser uma escola modelo em excelência, exemplo de comunidade escolar e social, valorizada pela comunidade.

Assim, recentemente estabeleceu novos padrões de sucesso escolar para o bairro, através do desenvolvimento constante de novas tecnologias para a aprendizagem dos alunos, e 0 atendimento individual para melhorar o desempenho de cada um, em seu tempo e ritmo, além de oferecer aos nossos alunos um ambiente acolhedor, com um espaço físico adequado, acolhendo de maneira elegante e apropriada alunos, pais, professores, funcionários e comunidade em geral que nela adentram.

A escola está inserida num cenário onde o desafio é assegurar aos seus alunos melhores resultados nos indicadores da Avaliação Externa (SARESP), bem como assegurar o direito de acesso e permanência dos mesmos na escola diminuindo a evasão escolar e a frequência irregular às aulas, com melhores condições pedagógicas e educativas, sendo uma escola inclusiva, tendo recebido desde 2013, alunos com deficiência auditiva e deficiência intelectual.

Com foco no alcance das metas supra mencionadas, a unidade escolar trabalha a análise da real situação do nível de escolarização e de aprendizagem, aplicação de projetos de leitura, recuperação contínua e intensiva, com professores de apoio a aprendizagem e com parceiros, aulas tecnológicas, saídas culturais para aprofundamento do conhecimento, além da inserção do Programa Mais Educação e PDE Interativo desde 2010.

O pré lançamento do projeto se dará no primeiro dia de aula, explicando aos pais, alunos e toda a comunidade escolar o Projeto "Hora da Virada", e após a aplicação da AAP, "Avaliação de Aprendizagem em Processo", realizada nos 10 primeiros dias de aula, na intenção de dar os rumos do PPP daquele ano e objetivando atender as necessidades de aprendizagem dos alunos, especialmente os que precisam de reforço e recuperação para atingir satisfatoriamente o proposto na série/ano/ciclo.

Desta forma, já teremos os primeiros grupos que participarão do projeto: "Hora da Virada", reforço e recuperação para nivelamento de desempenho em Língua Portuguesa, Matemática e outras disciplinas que se apontem defasadas, obtendo assim mais chances para o alcance das metas do IDESP.

Para viabilizar financeiramente 0 projeto, a escola contará com recursos do edital do Plano de Empreendimento, que será apresentado neste documento, no item Plano Financeiro.

Palavras-chaves: Educação. Recuperação escolar. Plano de empreendimento. 


\section{Renata Betareli}

\section{Contexto da escola}

A EE Professora Flávia Vizibeli Pirró atende atualmente ao ensino fundamental I em período integral e ao ensino fundamental II em período regular.

\section{Tem como Missão}

Oportunizar ao educando a construção efetiva de seu conhecimento, através de uma educação de qualidade, humanitária e adequada à sua realidade, visando qualidade de vida.

\section{Tem como Visão}

Ser uma escola modelo em excelência, exemplo de comunidade escolar e social, valorizada pela comunidade.

\section{Perfil da Comunidade Escolar}

Atende a alunos oriundos de uma realidade social muito deficitária, tanto financeira, quanto cultural e emocional.

A escola de tempo integral acaba sendo a melhor opção para as famílias que por ausência de bases mais estruturadas e organizadas, trabalham fora o dia inteiro em busca do sustento de todos. Deixando a cargo da escola, além do ensino, a guarda e segurança de seus filhos durante o dia.

O corpo docente é composto de efetivos na sua minoria, OFAS e contratados na sua maioria. $O$ que torna 0 trabalho da escola muito variável a cada ano, pela rotatividade de docentes contratados. Todos com a formação mínima exigida e poucos com especializações.

Há apenas 04 anos a escola mantém uma equipe gestora mais fixa.

A comunidade sempre foi pouco atuante e distante da escola. Aos poucos tem participado mais do projeto político pedagógico da escola, seja através dos colegiados, ou nas reuniões de pais e professores, ou ainda espontaneamente.

\section{Características Marcantes do Entorno}

A escola se insere em bairro residencial de classe média da zona sul de São Paulo. Os vizinhos são na maioria idosos. Porém sua clientela é de duas comunidades próximas: A favela Alba e beira rio, sendo a Alba uma das mais perigosas da cidade. Não é raro histórias de pais ou mães de alunos, presidiários, falecidos ou foragidos, cuidados por avós. A escola sofre evasão com o sumiço súbito de famílias foragidas e com 0 descaso dos direitos das crianças, que nesta situação fica em segundo plano.

\section{Histórico}

A escola teve sua inauguração na década de 50 e como grupo escolar naquela época atendia a educação infantil. $E$ foi na década de 60 que em novo prédio, passou a atender 0 ensino fundamental.

Com uma demanda muito flexível por circunstâncias locais até, atendeu ao longo das décadas todos os segmentos de ensino.

Participou do primeiro programa de escolas de tempo integral em 2006, para os dois ciclos do ensino fundamental e vivenciou inúmeros problemas com o programa para os dois segmentos em espaços insuficientes. Solicitando à SEE atendimento para apenas um dos ciclos acabou por ter que atender de maneira misturada, o ensino fundamental I em tempo integral, o ensino fundamental II em período regular, além do ensino médio e a educação de jovens e adultos no período noturno.

Hoje após reorganização, atende então ao ensino fundamental I em tempo integral e ao ensino fundamental II em período regular. Com tendência a especificar sua demanda em apenas ensino fundamental I, em novo modelo de ensino integral.

Recentemente recebeu parceria do Instituto GOL, através dos Parceiros da Educação. 


\section{Identificação do problema ou da oportunidade}

O processo educacional desenvolvido nos cinco últimos anos nesta Unidade Escolar vem sendo acompanhado com bastante cuidado devido suas alterações no desempenho dos alunos, que em ocasiões atingiram suas metas em até $120 \%$ nos anos inicias do ensino fundamental, em outras ocasiões nos anos finais. Demonstrando instabilidade em alguns anos.

Com a extinção do ensino médio, que muito atrapalhava o fluxo da escola, com o foco total no ensino fundamental e com um novo plano de ação, a escola conseguiu ampliar a porcentagem de alunos nos níveis básico e adequado do desempenho de aprendizagem, saindo da colocação crítica na Diretoria de Ensino onde nos encontrávamos, deixando de ser escola prioritária, por diminuir o índice de alunos no nível abaixo do básico.

Nossa conquista no IDESP 2013 foi de $120 \%$ na $8^{\text {a }}$ série do Ensino Fundamental, e de $55 \%$ no $5^{\circ}$ ano.

Concluímos que esse fato certamente foi possível pela participação de toda a comunidade escolar. Este ano reparamos um aumento significativo da presença dos pais nas reuniões, conselho de classe e convocações individuais, assim como um compromisso da equipe docente e gestora nas estratégias de melhoria da aplicação das aulas, uso do currículo e recursos tecnológicos. O perfil do aluno vem mudando aos poucos, demonstrando um aumento do interesse pelas aulas, pelas atividades extracurriculares, pela pesquisa e pelo conhecimento, melhorando sua frequência na escola, sua auto-estima e valorização aos estudos.

O aproveitamento das ATPCs é mais eficaz pela forma efetiva de participação de todos os professores do currículo e oficinas curriculares dos anos iniciais do ensino fundamental, verificando subsídios mais constantes e inovadores, assim como, o estudo e o desenvolvimento de ações que priorizem a efetivação das propostas, tanto para eles, como para os alunos e o tema gestão de sala de aula, carro chefe das discussões das ATPCs dos anos finais do ensino fundamental.

Contamos com o Acessa Escola que contribui muito para as pesquisas como novas formas de trabalho em sala de aula, onde a ação e reflexão permeiam todo o processo de construção do conhecimento, porém temos dificuldade na permanência de alunos estagiários.

Fomos contemplados várias vezes com o Programa Cultura é Currículo e dinamizamos o Programa Mais Educação com atividades diversificadas no contra turno, tanto para o ciclo I que já é de tempo integral na escola, como para o ciclo II.

O EMAI, "Educação Matemática nos Anos Iniciais", também tem adesão em nossa escola, assim como 0 PNAIC, "Pacto Nacional da Alfabetização na Idade Certa" e as ações do LER E ESCREVER.

O grande desafio da EE Professora Flávia Vizibeli Pirró ainda é assegurar aos seus alunos melhores resultados nos indicadores de Avaliação Externa (SARESP), bem como assegurar o direito de acesso e permanência dos mesmos na escola diminuindo a evasão escolar e a frequência irregular às aulas, com melhores condições pedagógicas e educativas, sendo uma escola inclusiva, tendo recebido em 2013, alunos com deficiência auditiva, mediado por interlocutor entre outras.

Dada a natureza específica do trabalho pedagógico e administrativo a ser realizado para alcançar este objetivo serão necessárias várias ações de intervenção interna e externa, bem como a articulação mais afinada entre todos os agentes envolvidos no processo educacional para assegurar o sucesso da aprendizagem e a melhoria da qualidade do ensino oferecido pela escola, as quais propomos em planos de ações, observáveis e acompanhados, como por exemplo, o PAP e o Prêmio Gestão, com foco nas dimensões pedagógicas e de resultados.

Esse ano de 2014 teremos a oportunidade de receber o apoio dos Parceiros da Educação. Que muito vem ajudando as escolas no trabalho pedagógico para o avanço do desempenho dos alunos e para a melhoria do atendimento e manutenção das instalações. 


\section{Renata Betareli}

\section{Diante desta perspectiva, apresento:}

0 problema: manter os índices de desempenho escolar em crescimento, elevando o número de alunos nos níveis adequado e avançado, diminuindo o número de alunos nos níveis abaixo do básico e básico.

A comprovação da existência do problema: resultado dos últimos 04 anos da avaliação externa (SARESP). Que apresenta muita oscilação e instabilidade.

A história do problema, origem e contexto: presente na própria história da escola desde a década de 60 , da clientela atendida, de problemas sociais, de rotatividade de professores ou ausência deles, da evasão e da frequência irregular, entre outros contextos.

0 cenário futuro: alcance das metas ano a ano, oferecendo a melhor qualidade de ensino aos alunos.

As soluções: reforço e recuperação de alunos que apresentam dificuldades, aplicação de avaliações diagnósticas, formação de professores, parceria da família, projetos de leitura, atividades extraclasse.

As escolhas: todas as ações concomitantes.

\section{As etapas:}

Avaliações diagnósticas

\section{Reforço e recuperação}

Formação de professores e parceria com a família

Projetos de leitura e atividades extraclasses

A oportunidade: este plano tem como oportunidade para a unidade escolar, a mudança de sua fama na comunidade. Quando mantínhamos o ensino médio,

a escola foi considerada e publicada por toda a mídia como a escola de pior índice do ensino médio no Estado de São Paulo. Mesmo apresentando índices melhores no ensino fundamental, sempre o que foi evidenciado pela comunidade eram os resultados ruins, trazidos pelo ensino médio.

\section{Caracterização do produto/serviço e/ou processo}

A escola passará a atender em período oposto as aulas, os alunos destacados na primeira avaliação diagnóstica, com defasagem nas disciplinas de Língua Portuguesa e Matemática, para que consigam superar durante 0 ano letivo suas deficiências e seguir o currículo proposto para a série matriculada.

A avaliação diagnóstica é a primeira etapa deste projeto. Porém como a mesma já esta presente na rotina da unidade escolar, sendo aplicada por seus próprios professores e enviada pela Secretaria de Educação em acordo com o currículo da rede estadual, será esta uma etapa sem custos e sem grandes mudanças na escola.

A novidade do projeto estará na oportunidade do aluno ter um atendimento mais individualizado, em pequenos grupos e se utilizando de recursos áudio visuais e tecnológicos que ajudam a acelerar o processo de ensino-aprendizagem.

Funcionará de segunda a sexta-feira para atender diversos grupos, no mínimo 02 vezes na semana. Tanto no período da manhã quanto da tarde, atenderá aos alunos do ensino fundamental II e simultaneamente as oficinas da ETI (escola de tempo integral), atenderá alunos do ensino fundamental I.

Os especialistas para este atendimento precisarão ter formação pedagógica e habilidade com as ferramentas tecnológicas, portais educacionais, plataformas de jogos entre outros recursos didáticos informatizados. Os mesmos serão contratamos com os recursos deste edital e por análise de currículo e entrevista da equipe gestora da unidade escolar. Sendo a montagem de turma de no máximo 06 alunos e a contratação dos especialistas, a segunda etapa da implantação do projeto.

Concomitante a isso, uma terceira etapa do projeto terá foco no corpo docente da escola que receberá 
formação específica sobre temas como: novas metodologias e recursos tecnológicos, formas de avaliação qualitativa e formativa. Compartilhando sempre com o especialista do reforço nas reuniões de ATPCs, os avanços dos aprendizes. Nesta terceira fase os familiares também receberão atenção especial, sendo convidados a participar de palestras informativas e de orientação para uma parceria eficaz de acompanhamento do desempenho escolar de seu filho.

O projeto vai evoluir ou se desdobrar na medida em que superada as deficiências, os alunos possam ampliar seus conhecimentos com o hábito do estudo diário, da pesquisa e da leitura, atingindo então a quarta etapa, que será o projeto de leitura e atividades extraclasse.

Ambos estarão presentes no próprio planejamento dos professores, que pensarão as atividades mais adequadas e compatíveis com o currículo sugerindo locais de observação e estudo, como museus, laboratórios, exposições, entre outros locais para aquisição do saber. E literatura que favoreçam tanto 0 conhecimento quanto o gosto, 0 deleite pela leitura.

A reportagem a seguir, demonstra algumas iniciativas de reforço e recuperação de alunos em escolas brasileiras, que acreditam em novos modelos de avaliação e acompanhamento do desempenho dos alunos e no trabalho parceiro dos professores de recuperação e do currículo de sala de aula.

\section{0 reforço que funciona}

Realizar um trabalho constante ao longo do ano é a melhor forma de lidar com os diversos níveis de aprendizagem em sala de aula. Verônica Fraidenraich (gestaoescolar@fvc.org.br)
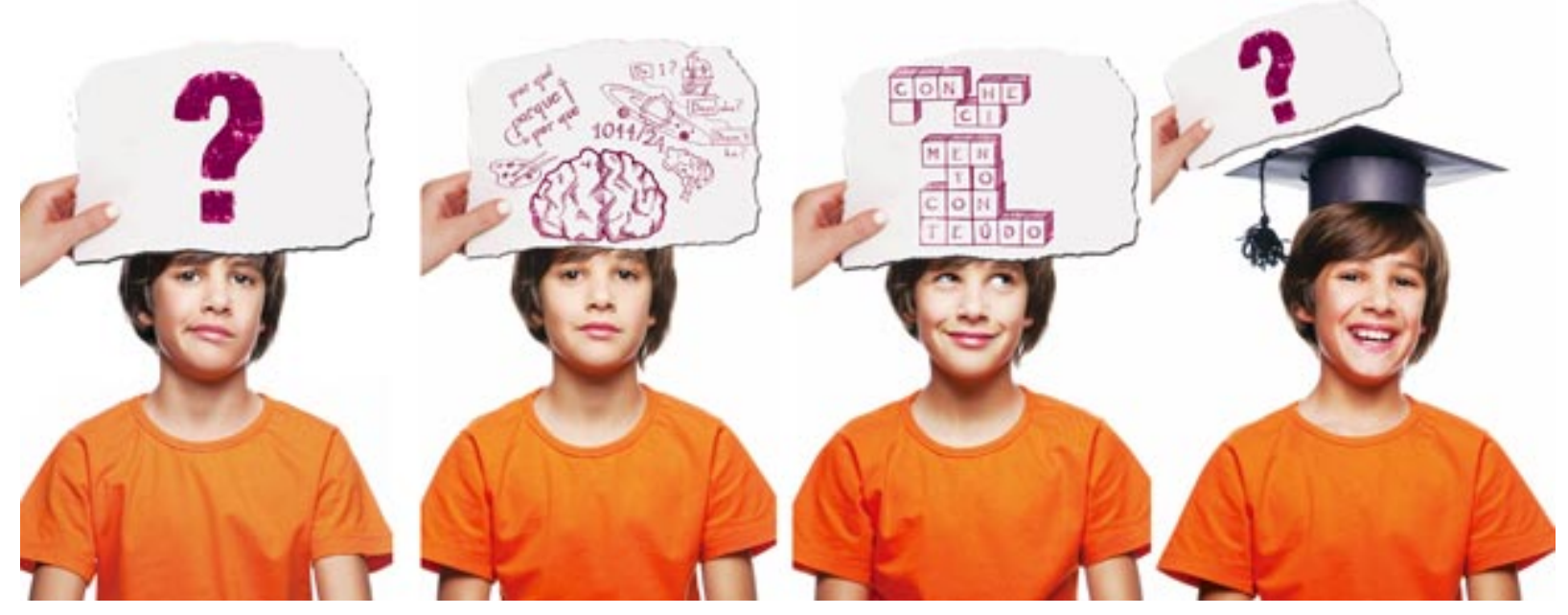

Nenhum aluno gosta de ficar de recuperação. Além de ter de enfrentar um possível rótulo - "criança com dificuldade de aprendizagem" -, os estudantes nessa situação encaram a pressão de serem obrigados a fazer uma única prova, decisiva, para saber se serão aprovados ou não.

Hoje, porém, sabe-se que não é recomendável esperar o fim do ano para ajudar os que não têm o desempenho esperado. Isso porque em uma turma sempre existirão diferentes níveis de aprendizagem - e isso não quer dizer que os alunos não tenham capacidade de aprender, apenas que cada um avança com ritmo próprio. À escola cabe, portanto, detectar a diversidade presente nas salas de aula e criar condições para que os conteúdos trabalhados, quando não são bem compreendidos, sejam retomados em classe com novas atividades e estratégias de ensino.

Esse é o tema da reportagem de capa da edição de setembro de NOVA ESCOLA, que responde a 11 dúvidas que os professores enfrentam sobre o assunto - do diagnóstico à lição de casa. "A recomendação é avançar e retroceder ao mesmo tempo, fazendo com que quem atinge o conhecimento esperado continue aprendendo, enquanto os demais trabalham as dúvidas assim que elas surgirem", diz Maria Celina Melchior, professora de pós-graduação em Educação e coordenadora pedagógica da Faculdade Novo Hamburgo, na Grande Porto Alegre. 


\section{Renata Betareli}

Para saber com que alunos é possível ir adiante e com quais é preciso retomar os conteúdos, é necessário usar bem as ferramentas de avaliação. $O$ diagnóstico inicial, as provas, a observação de sala de aula, as atividades de sondagem, as tarefas de casa e a análise de cadernos e portifólios são alguns dos instrumentos que ajudam a ter um panorama da turma. O que não vale é olhar apenas as notas das provas. "As avaliações bem feitas têm questões e atividades que já foram trabalhadas em sala de aula e não criam 'pegadinhas' para o aluno", afirma Cipriano Luckesi, da Universidade Federal da Bahia (UFBA).

Com os resultados, a coordenação pedagógica pode orientar a equipe docente a organizar as informações. As dificuldades apresentadas em determinada disciplina podem ser classificadas de acordo com o conteúdo e a frequência com que aparecem. Isso dará mais clareza em relação aos pontos que devem ser retomados. Quando um ponto não foi entendido pela maioria do grupo, o melhor é procurar com o professor uma abordagem diversificada da usada até então e orientá-lo a retomar o tema com a classe toda. Caso a conclusão seja de que a turma apresenta dificuldades diferentes, o ideal é formar grupos e oferecer atividades específicas para cada um. Pode ser também que apenas um aluno esteja com problema em determinado ponto. A sugestão, então, é oferecer a ele um conjunto de atividades que podem ser feitas em casa e depois corrigidas pelo professor.

Também é função dos gestores ajudarem na organização dos agrupamentos de trabalho em sala de aula. Rose Maria Antunes de Barros, coordenadora pedagógica da Escola Castanheiras, em Santana de Parnaíba, na Grande São Paulo, e autora de um estudo sobre grupos de apoio em escolas, dá algumas sugestões. Para atender os diversos grupos ao mesmo tempo, o professor tem de fazer um bom planejamento das aulas, com sequências didáticas ajustadas às necessidades de aprendizagem.

O interessante é que o coordenador pedagógico colabore na construção de um banco de atividades variadas, que o docente deve ter no seu arquivo, para usar quando necessário e contemplar o maior número possível de alunos. Também é importante orientá-lo a alternar o uso de materiais pedagógicos - como vídeos, músicas e revistas - e estratégias diversificadas - aulas expositivas, estudos de campo, pesquisas e trabalhos em grupo - como uma maneira de atender às diferentes formas de os estudantes aprenderem.

Se as atividades de reforço precisarem ser realizadas em horários no contra turno, cabe aos gestores garantir um espaço ideal para que elas aconteçam. $O$ professor titular da turma necessita ainda de um tempo reservado para a troca de informações com o colega responsável pela recuperação. Na pauta do encontro, devem estar as necessidades dos alunos e a maneira com que eles serão acompanhados e avaliados para ter a garantia de que possam continuar avançando.

\section{Estratégia de implementação}

A seguir são apresentadas as forças, fraquezas, oportunidades e ameaças do projeto. Além disso, também estão descritos abaixo, os objetivos, a estratégia de implementação, os indicadores para acompanhamento, os recursos necessários e forma de obtenção desses recursos.

\section{Análise FOFA}




\begin{tabular}{|c|c|}
\hline FORÇAS & OPORTUNIDADES \\
\hline $\begin{array}{l}\text { Planejamento que indica no início do ano o } \\
\text { compromisso de todo o corpo docente em realizar a } \\
\text { avaliação diagnóstica. }\end{array}$ & $\begin{array}{l}\text { Avaliação diagnóstica enviada pela SEE, em acordo } \\
\text { com o currículo da rede estadual. }\end{array}$ \\
\hline $\begin{array}{l}\text { Instalação de rede internet nos vários ambientes da } \\
\text { escola. }\end{array}$ & $\begin{array}{l}\text { Programa Currículo Mais, sendo oferecido aos } \\
\text { professores, para o uso de novas tecnologias aliada aos } \\
\text { conteúdos do currículo. }\end{array}$ \\
\hline FRAQUEZAS & AMEAÇAS \\
\hline $\begin{array}{l}\text { Ausência de legislação para frequencia obrigatória as } \\
\text { aulas de reforço e recuperação pelos alunos que } \\
\text { apresentarem na } A D \text { baixo desempenho. }\end{array}$ & $\begin{array}{l}\text { Adesão do aluno, já que sendo o projeto oferecido no } \\
\text { horário oposto as aulas, sua frequência não pode ser } \\
\text { obrigatória. Sendo esperados, compromisso e } \\
\text { responsabilidade do próprio aluno e da família. }\end{array}$ \\
\hline Contratação dos especialistas. & $\begin{array}{l}\text { Oferta de profissionais com as habiliades e formação } \\
\text { necessárias. }\end{array}$ \\
\hline
\end{tabular}




\section{Renata Betareli}

\section{Objetivos}

\begin{tabular}{|c|c|c|}
\hline \multicolumn{3}{|l|}{ Definição das estratégias } \\
\hline Objetivos & Metas & Estratégias \\
\hline $\begin{array}{l}\text { Atingir as metas do } \\
\text { IDESP previstas para } \\
2015,2016 \text { e } 2017\end{array}$ & $\begin{array}{l}\text { Diminuir em } 100 \% \text { o número de } \\
\text { alunos abaixo do básico nas } \\
\text { avaliações externas }\end{array}$ & $\begin{array}{l}\text { Realizar a avaliação diagnóstica para destacar os } \\
\text { alunos com baixo desempenho nas disciplinas } \\
\text { avaliadas pelo SARESP - Matemática e Língua } \\
\text { Portuguesa. } \\
\text { Montar e oferecer aos alunos reforço e } \\
\text { recuperação em pequenos grupos, no período } \\
\text { inverso as aulas, com professor especialista. } \\
\text { Oferecer palestras informativas e de orientação } \\
\text { aos pais para uma parceria eficaz no } \\
\text { desenvolvimento de seu filho. } \\
\text { Capacitar o corpo docente em novas metodologias, } \\
\text { tecnologias educacionais e avaliação qualitativa. }\end{array}$ \\
\hline
\end{tabular}

\section{Plano de ação}

\begin{tabular}{|c|c|c|c|c|c|c|c|}
\hline O que? & Quem? & Onde? & Quando? & Por quê? & Como? & \multicolumn{2}{|c|}{ Quanto? } \\
\hline $\begin{array}{l}\text { Aplicação da } \\
\text { AD }\end{array}$ & $\begin{array}{l}\text { Profes- } \\
\text { sores }\end{array}$ & $\begin{array}{l}\text { Salas de } \\
\text { aula }\end{array}$ & $\begin{array}{ll}\text { Mês de } \\
\text { fevereiro de } \\
\text { cada ano de } \\
\text { projeto }\end{array}$ & $\begin{array}{l}\text { Indicar alunos } \\
\text { para reforço e } \\
\text { recupera-ção }\end{array}$ & $\begin{array}{l}\text { Por instrumento } \\
\text { específico }\end{array}$ & $\begin{array}{l}\text { Ação } \\
\text { custo }\end{array}$ & sem \\
\hline $\begin{array}{l}\text { Montagem de } \\
\text { turmas para } \\
\text { R/R }\end{array}$ & $\begin{array}{l}\text { Coorde- } \\
\text { nadores }\end{array}$ & $\begin{array}{l}\text { Unid. } \\
\text { escolar }\end{array}$ & $\begin{array}{l}\text { Mês de março } \\
\text { de cada ano } \\
\text { de projeto }\end{array}$ & $\begin{array}{l}\text { Verificar } \\
\text { número de } \\
\text { turmas para } \\
\text { contratação }\end{array}$ & $\begin{array}{l}\text { Montando } \\
\text { grupos de } 06 \\
\text { alunos, com } \\
\text { proximidade de } \\
\text { desempenho }\end{array}$ & $\begin{array}{l}\text { Ação } \\
\text { custo }\end{array}$ & sem \\
\hline $\begin{array}{l}\text { Contratar } \\
\text { Profos } \\
\text { especialistas }\end{array}$ & Diretor & $\begin{array}{l}\text { Unid. } \\
\text { escolar }\end{array}$ & $\begin{array}{l}\text { Mês de março } \\
\text { de cada ano } \\
\text { de projeto }\end{array}$ & $\begin{array}{l}\text { Dar início as } \\
\text { aulas de } R / R\end{array}$ & $\begin{array}{lr}\text { Através } & \text { de } \\
\text { currículo } & \text { e } \\
\text { entrevista } & \end{array}$ & $\begin{array}{l}\text { Ação } \\
\text { custo }\end{array}$ & sem \\
\hline $\begin{array}{lr}\text { Promover } & \\
\text { palestra para os } \\
\text { pais } & \text { de } \\
\text { informação } & \text { e } \\
\text { orientação } & \end{array}$ & $\begin{array}{l}\text { Equipe } \\
\text { gestora }\end{array}$ & $\begin{array}{l}\text { Unid. } \\
\text { escolar }\end{array}$ & $\begin{array}{lr}\text { Meses de } \\
\text { março, junho, } \\
\text { agosto } \\
\text { outubro de } \\
\text { cada ano de } \\
\text { projeto }\end{array}$ & $\begin{array}{l}\text { Para uma } \\
\text { parceria } \\
\text { eficaz no } \\
\text { desenvolvi- } \\
\text { mento do seu } \\
\text { filho }\end{array}$ & $\begin{array}{l}\text { Planejando com } \\
\text { a equipe } \\
\text { gestora, } \\
\text { preparando os } \\
\text { temas e } \\
\text { recebendo-os } \\
\text { na escola }\end{array}$ & $\begin{array}{l}\text { Ação } \\
\text { custo }\end{array}$ & sem \\
\hline & & & & & & & \\
\hline
\end{tabular}




\section{Hora da virada}

\begin{tabular}{|l|l|l|l|l|l|l|}
\hline $\begin{array}{l}\text { Adquirir tablets } \\
\text { para utilização } \\
\text { dos alunos }\end{array}$ & Diretor & Fornece-dor & $\begin{array}{l}\text { Mês } \\
\text { abril de cada } \\
\text { ano de projeto } \\
\text { se neces- } \\
\text { sário }\end{array}$ & $\begin{array}{l}\text { Para uso de } \\
\text { tecnologias } \\
\text { educacionais }\end{array}$ & $\begin{array}{l}\text { Através de } \\
\text { orçamentos }\end{array}$ & $\begin{array}{l}\text { R 300,00 } \\
\text { Por } \\
\text { participante }\end{array}$ \\
\hline $\begin{array}{l}\text { Oferecer } \\
\text { formação para } \\
\text { professores }\end{array}$ & Parceiro & $\begin{array}{l}\text { Unid. } \\
\text { escolar }\end{array}$ & $\begin{array}{l}\text { Nos períodos } \\
\text { de planeja- } \\
\text { mento e } \\
\text { ATPC }\end{array}$ & $\begin{array}{l}\text { Para melhorar } \\
\text { a prática de } \\
\text { sala de aula }\end{array}$ & Em serviço & Valor \\
pesquisar
\end{tabular}

\section{Indicadores para acompanhamento do projeto}

Avaliações periódicas e específicas aos participantes do projeto de Reforço e Recuperação.

Acompanhamento pela coordenação da gestão de sala de aula dos professores participantes da formação.

Atas das reuniões de ATPCs.

Atas dos conselhos de classe.

Atas de reuniões de pais.

\section{Recursos necessários}

\begin{tabular}{|c|c|c|}
\hline \multicolumn{3}{|l|}{ Recursos necessários } \\
\hline O que vou precisar & Descrição & Como obter \\
\hline $\begin{array}{l}\text { Folha de pagamento dos } \\
\text { professores de Reforço e } \\
\text { Recuperação }\end{array}$ & $\begin{array}{l}\text { Como o Estado não prevê professor para } \\
\text { essa ação na escola os recursos seriam } \\
\text { destinados para pagamento dos } \\
\text { professores especialistas que trabalhariam } \\
\text { em regime autônomo }\end{array}$ & $\begin{array}{l}\text { Obtendo os recursos do edital em } \\
\text { questão }\end{array}$ \\
\hline $\begin{array}{lr}\text { Aquisição de } & \text { materiais } \\
\text { pedagógicos } & \mathrm{e} \\
\text { tecnológicos } & \end{array}$ & $\begin{array}{l}\text { Para permitir atendimento nas aulas de } \\
\text { reforço com ferramentas e recursos } \\
\text { inovadoras }\end{array}$ & $\begin{array}{l}\text { Recursos deste edital ou de verba } \\
\text { destinada para a aquisição de capital do } \\
\text { governo federal PDDE }\end{array}$ \\
\hline Formação de professores & $\begin{array}{l}\text { Para oferecer melhoria na gestão de sala } \\
\text { de aula pelos professores do currículo }\end{array}$ & $\begin{array}{l}\text { Recursos deste edital ou recursos da } \\
\text { Parceria } \\
\text { "Parceiros da Educação" } \\
\text { Instituto GOL }\end{array}$ \\
\hline
\end{tabular}




\section{Renata Betareli}

\section{Marketing e Comunicação}

O lançamento do projeto se dará no primeiro dia de aula do ano letivo, no momento do acolhimento dos alunos e de seus pais, que geralmente acontece no pátio da escola.

A equipe gestora preparará apresentação multimídia que demonstre os resultados obtidos pelos alunos da unidade escolar, nos últimos 03 anos de aplicação da avaliação externa.

Como será possível verificar, a escola que já esteve em situação prioritária, hoje, conseguiu atingir a meta prevista para o ano em questão.

Sendo assim, o desafio será lançado para alunos, pais e professores pela manutenção das metas e pelo fortalecimento dos alunos que ainda se encontram no nível abaixo do básico.

Uma descrição detalhada do que pretendemos e do que iremos oferecer será realizada em multimídia também.

Entregaremos aos pais um panfleto explicativo das etapas do projeto, dando destaque aos momentos que serão dedicados a eles, os pais.

Continuaremos a realizar as comunicações do projeto através de comunicados via agenda dos alunos, ou email da família cadastrado na secretaria digital. A comunicação com os professores será mantida nas ATPCs. Os resultados obtidos ao longo do projeto serão enviados ao parceiro e à instituição responsável deste edital, em gráficos quantitativos e relatórios qualitativos.

\section{Organização e gerência do empreendimento}

Planejar, organizar e gerir é uma atividade inerente ao ser humano. Na época em que vivemos, em que fatos e descobertas cientificas desse mundo conectado, transmitidos instantaneamente, geram reflexos imediatos nas pessoas bem como nas organizações, mais do que nunca, planejar é fundamental.

E aí está o ser humano, que no dia a dia, sempre enfrenta situações que necessitam de planejamento. 0 presente plano surgiu, após reflexões intensas da equipe escolar, visto a necessidade de uma nova organização do grupo escola para melhorar 0 atendimento aos alunos da unidade escolar que vem apresentando defasagem de aprendizagem . E assim, a cada passo ele foi sendo construído, tendo como base 0 propósito de todos da unidade escolar que em linhas gerais destaca o que ela faz, para que ela existe, onde pretende chegar e quais as formas e princípios de atuação, refletidos na missão, visão e valores.

Para tanto apresentamos nesta seção a descrição da equipe envolvida e responsável pela execução das tarefas que nos levarão a alcançarmos o objetivo proposto

\begin{tabular}{|l|l|l|l|}
\hline NOME & CARGO & FORMAÇÃO/EXPERIÊNCIA & FUNÇÃO NO PROJETO \\
\hline Renata Betareli & Diretora & Pedagogia & Coordenação Geral \\
& & Especialização latu sensu Gestão de Escola Pública & \\
& & USP & \\
& & MBA Gestão Empreendedora UFF & \\
& & 10 anos - professor PEB II & \\
& & 06 anos - coordenador pedagógico & \\
& & 11 anos - gestora (diretora efetiva há 05) & \\
& & & \\
\hline
\end{tabular}




\begin{tabular}{|c|c|c|c|}
\hline $\begin{array}{l}\text { Rita Enoe Busson } \\
\text { Barbosa }\end{array}$ & Vice-Diretor & $\begin{array}{l}\text { PEB I } \\
30 \text { anos - PEB I SEE } \\
02 \text { anos - vice diretor } \\
\text { Professora aposentada da PMSP }\end{array}$ & $\begin{array}{l}\text { Acompanhamento } \\
\text { administrativo/Controle Financeiro }\end{array}$ \\
\hline Vilma Ventura Cruz & $\begin{array}{l}\text { Coordenadora } \\
\text { Pedagógica }\end{array}$ & $\begin{array}{l}\text { PEB II Ciências Biológicas } \\
\text { Especialização latu sensu Coordenação de Currículo } \\
\text { USP } \\
18 \text { anos - professor PEB II } \\
12 \text { anos - coordenador pedagógico }\end{array}$ & $\begin{array}{l}\text { Acompanhamento e orientação } \\
\text { pedagógica }\end{array}$ \\
\hline $\begin{array}{l}\text { Alexandra Agnone Alves } \\
\text { Sena }\end{array}$ & $\begin{array}{l}\text { Coordenadora } \\
\text { Pedagógica }\end{array}$ & $\begin{array}{l}\text { PEB I } \\
06 \text { anos - PEB I } \\
02 \text { anos - coordenador pedagógico }\end{array}$ & $\begin{array}{l}\text { Acompanhamento e orientação } \\
\text { pedagógica }\end{array}$ \\
\hline Rose Domenicis & $\begin{array}{l}\text { Gerente de } \\
\text { Organização Escolar }\end{array}$ & $\begin{array}{l}35 \text { anos na SEE cargo efetivo de secretario escolar } \\
\text { Ensino Médio }\end{array}$ & Organização e controle da escrituração \\
\hline Rejivânia Batista & $\begin{array}{l}\text { Agente de } \\
\text { Organização Escolar }\end{array}$ & $\begin{array}{l}03 \text { anos na SEE } \\
\text { Ensino Médio }\end{array}$ & Auxiliar no controle e escrituração \\
\hline Ajax Moura Tojeiro Filho & Professor Mediador & $\begin{array}{l}\text { PEB II Educação Física } \\
02 \text { anos na mediação }\end{array}$ & $\begin{array}{l}\text { Acompanhar a freqüência do aluno nas } \\
\text { aulas de reforço e recuperação assim } \\
\text { como as aulas regulares }\end{array}$ \\
\hline Ana Maria Lhano & $\begin{array}{l}\text { Professor de } \\
\text { Educação Básica }\end{array}$ & $\begin{array}{l}\text { PEB II Matemática } \\
\text { Efetiva há } 18 \text { anos }\end{array}$ & $\begin{array}{l}\text { Desenvolver o conteúdo de matemática } \\
\text { e aplicar as avaliações }\end{array}$ \\
\hline Janaina Silva & $\begin{array}{l}\text { Professor } \\
\text { Educação Básica }\end{array}$ & $\begin{array}{l}\text { PEB II Português } \\
\text { Efetiva há } 10 \text { anos } \\
\text { Mestre em Educação }\end{array}$ & $\begin{array}{l}\text { Desenvolver o conteúdo de português e } \\
\text { inglês e aplicar as avaliações }\end{array}$ \\
\hline $\begin{array}{lll}\text { Maria } & \text { do } & \text { Carmo } \\
\text { Carvalho } & \end{array}$ & $\begin{array}{l}\text { Professor } \\
\text { Educação Básica }\end{array}$ & $\begin{array}{l}\text { PEB I } \\
\text { Cat.F há } 18 \text { anos }\end{array}$ & $\begin{array}{l}\text { Desenvolver } 0 \text { conteúdo de } \\
\text { alfabetização e matemática e aplicar as } \\
\text { avaliações }\end{array}$ \\
\hline
\end{tabular}

\section{Plano financeiro}

A construção desse plano surgiu portanto, com o objetivo de melhorar a aprendizagem dos alunos, através da inserção de espaços de aprendizagem mais significativa, tanto para alunos como para os docentes.

O foco é a análise dos resultados dos anos anteriores, com posterior ação para melhorar os índices da avaliação externa.

Assim, depois de elaborar e traçar o caminho a ser percorrido para alcançar o sucesso escolar, esta equipe levantou as implementações necessárias para a viabilização do projeto, bem como o capital necessário para a realização e aquisição de materiais, tanto de custeio quanto de capital.

Todavia, é preciso destacar que, os esforços em recuperação do desempenho do aluno, seja por aulas 


\section{Renata Betareli}

tradicionais ou por aulas dinamizadas pela aquisição de equipamentos, instalações de softwares educacionais, em nada alterarão a rotina da escola se, os docentes não internalizarem todo o processo de mudança, buscando inserir 0 aproveitamento contínuo da aprendizagem do aluno com as novidades tecnológicas no cotidiano de suas aulas, como meio e não fim no processo educacional

Demonstramos a seguir algumas das aplicações necessárias e que contribuirão de forma impar para o seu desenvolvimento em processo, para promover toda a comunidade, mas em especial o professor e seus alunos, conforme o que demonstra as planilhas detalhando as aplicações do projeto

em foco. A viabilização financeira é possível visto que os valores a serem empenhados condizem com os valores do edital deste projeto.

\section{Investimentos (despesas de capital)}

\begin{tabular}{|l|l|l|l|}
\hline Item & Ano1 & Ano2 & Ano3 \\
\hline Obras e infraestrutura & 0,00 & 0,00 & 0,00 \\
\hline Obras & 0,00 & 0,00 & 0,00 \\
\hline Instalações & 0,00 & 0,00 & 0,00 \\
\hline Material permanente & $12.000,00$ & 0,00 & 0,00 \\
\hline Equipamentos & & 0,00 & 0,00 \\
\hline Tablets & $12.000,00$ & 0,00 & 0,00 \\
\hline Total & $12.000,00$ & 0,00 & 0,00 \\
\hline
\end{tabular}

\begin{tabular}{|c|c|c|c|c|}
\hline \multicolumn{4}{|l|}{ Cálculo da Necessidade de Recursos } & \multirow[b]{2}{*}{ TOTAL } \\
\hline Item & ANO 1 & ANO 2 & ANO 3 & \\
\hline I. Total das Despesas Correntes & $30.380,00$ & $15.020,00$ & $2.030,00$ & $47.430,00$ \\
\hline Material de Consumo & $4.880,00$ & $2.020,00$ & $2.030,00$ & $8.930,00$ \\
\hline $\begin{array}{llll}\begin{array}{l}\text { Passagens } \\
\text { Locomoção }\end{array} & \text { e } & \text { Despesas } & \text { com } \\
\end{array}$ & $7.500,00$ & 0,00 & 0,00 & $7.500,00$ \\
\hline Serviços de Terceiros & $18.000,00$ & $13.000,00$ & 0,00 & $31.000,00$ \\
\hline II. Total de Despesas Administrativas & 840,00 & 840,00 & 840,00 & $2.520,00$ \\
\hline III. Total de Despesas com Pessoal & $7.200,00$ & $7.200,00$ & $7.200,00$ & $21.600,00$ \\
\hline $\begin{array}{l}\text { IV. Total de Despesas de Capital } \\
\text { (investimentos) }\end{array}$ & $12.000,00$ & 0,00 & 0,00 & $12.000,00$ \\
\hline Necessidade de Recursos (I+II+|II+IV) & $50.420,00$ & $23.060,00$ & $10.070,00$ & $83.550,00$ \\
\hline Recursos Edital & $45.378,00$ & $20.754,00$ & $9.063,00$ & $75.195,00$ \\
\hline 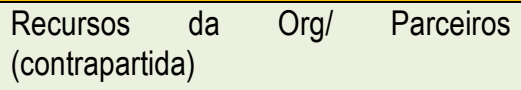 & $5.042,00$ & $2.306,00$ & 1007,00 & $8.355,00$ \\
\hline
\end{tabular}

